$57 \mid 2016$

Innovations pédagogiques dans l'enseignement des langues étrangères : perspective historique (XVle-XXle siècles)

\title{
La adaptación a aprendientes hispanohablantes de la Gramatica francesa de Pierre-Paul Billet
}

Irene Valdés Melguizo

\section{OpenEdition \\ Journals}

\section{Electronic version}

URL: https://journals.openedition.org/dhfles/4409

DOI: $10.4000 /$ dhfles.4409

ISSN: 2221-4038

\section{Publisher}

Société Internationale pour l'Histoire du Français Langue Étrangère ou Seconde

\section{Printed version}

Date of publication: 1 December 2016

Number of pages: 117-135

ISSN: 0992-7654

\section{Electronic reference}

Irene Valdés Melguizo, "La adaptación a aprendientes hispanohablantes de la Gramatica francesa de Pierre-Paul Billet", Documents pour I'histoire du français langue étrangère ou seconde [Online], 57 | 2016, Online since 01 February 2018, connection on 26 March 2023. URL: http://journals.openedition.org/ dhfles/4409 ; DOI: https://doi.org/10.4000/dhfles.4409

This text was automatically generated on 26 March 2023.

All rights reserved 


\title{
La adaptación a aprendientes hispanohablantes de la Gramatica francesa de Pierre-Paul Billet
}

\author{
Irene Valdés Melguizo
}

\section{Introducción}

La Gramatica francesa de Pierre-Paul Billet $(1673,1688,1708)$ (de ahora en adelante Billet) ha suscitado el interés de varios investigadores que trabajan en el campo de la historia de la enseñanza de francés en España. Es el caso de D. Fischer $(1996,2000)$, B. Lépinette (1997, 2000), M. Bruña (2010a, 2010b) ${ }^{1}$, y, de modo parcial, J. Suso (2011, 2014), y recientemente, de M. Viémon (2016, tesis doctoral) y A. Yllera (2016). Diferentes aspectos de esta gramática han sido puestos de relieve así : la biografía del autor, las diferentes ediciones, la organización de la obra, la pronunciación, el contenido gramatical, el léxico, el método o el enfoque pedagógico, el proceso contrastivo, el metalenguaje... Todos ellos han señalado así el carácter ineludible de esta gramática en la historia de la enseñanza de francés en España.

2 Nuestro artículo tiene por fin no sólo de reunir estos diferentes estudios, dispersos y parciales, para ofrecer una visión de conjunto de su gramática, tomando como objeto principal las aportaciones y las innovaciones que Billet introduce en esta gramática, con relación a las gramáticas francesas de la época, publicadas en España, en Francia, o bien en otros países (entre otras, las de D. de Cisneros, 1635, de Ch. Maupas, 1607-1635, o de L. Chifflet, 1659). Esperamos que esta visión de conjunto permita comprender mejor su calidad de obra fundadora de las gramáticas de francés editadas en España a lo largo del siglo XVIII, carácter que le otorga M. Bruña, como veremos más adelante. Nuestro análisis nos ha permitido descubrir por otra parte una serie de aspectos que todavía no se habían puesto de relieve, que muestran la originalidad profunda del autor. Responde precisamente nuestro trabajo a la invitación que lanza M. Bruña al final de su estudio (2010b) : es su lectura la que nos despertó el interés por este autor, y 
vamos a tratar de cumplir su deseo que otros investigadores completen cuestiones que él mismo no tuvo tiempo de aclarar. La Gramatica francesa de Billet, como defiende M. Bruña en dos estudios (2010a y 2010b) que le dedica a este autor, debe ser considerada como la obra fundadora de la serie constituida por la modalidad de obras comúnmente llamada 'gramática de francés destinada a españoles' : « antes de él se habían editado esporádicamente algunas gramáticas de francés para españoles, con él comienza la serie ininterrumpida de este tipo de obras que llega hasta nuestro días» (2010b : 257). Estamos de acuerdo con la distinción concedida a esta obra por M. Bruña: las gramáticas que la preceden datan de 1624-1635 (D. de Cisneros) y de 1647 (Sotomayor, reeditado por Lacavallería) no inauguran ninguna serie y no constituyen un modelo sobre el que asentar un tipo de obra (gramática del francés para españoles) ${ }^{2}$. Por el contrario, el modelo de composición cambia, con y a partir de la Gramatica francesa de Billet, como expondremos a continuación.

¿Qué características presenta la Gramatica francesa Billet? Vamos a proceder, desde un punto de vista metodológico, siguiendo un orden cronológico al análisis de las diferentes ediciones de 1673, de 1688 y de 1703, y posteriormente marcaremos las diferencias que pueden ser observadas comparando las diferentes, ya que muestran bien la evolución de este maestro de lenguas en su concepción de la gramática como útil de enseñanza y aprendizaje de una lengua extranjera, en este caso, el francés. La edición de 1673 lleva por título :

Gramatica francesa, dividida en dos partes. La primera contiene los primeros rudimentos, con observaciones curiosísimas sobre las partes de la Oración. La segunda comprehende vn tratado muy por extenso de la Oración, ó construcción; con vn Paralelo de la Eloquencia Española, y Francesa ; y Francesa y Española. Con un Arte poética, o breve compendio de la Poesía Francesa, vtilissimo para aprender à conocer los versos, $\mathrm{y}$ à componerlos.

4 Y la edición de ${ }^{2} 1688$ (destacamos en negrita los cambios):

Gramatica francesa, dividida en tres partes. La primera. Contiene los primeros rudimentos, con observaciones curiosísimas sobre las partes de la Oración, y nuevamente añadidas. La segunda. Comprehende vn tratado muy por extenso de la Oración, ó construcción, mas amplio que en la primera edición; con vn Paralelo de la Eloquencia Española, y Francesa ; y Francesa y Española, aumentado de mas de vna tercia parte en esta segunda Edicion, de las expresiones mas cortesanas de el Idioma Francés. La tercera. Contiene vn Arte poética, o breve compendio de la Poesía Francesa, vtilissimo para aprender à conocer, y medir los versos, y à componerlos.

5 En cuanto a la edición de Amberes (fechada en los catálogos en 1687, pero que M. Bruña considera posterior a 1688) es igualmente una copia exacta de la edición de ${ }^{2} 1688$ pero con algunos cambios como confirma Yllera :

Tout semble indiquer que cette édition est postérieure à l'édition de Madrid, 1688, et qu'elle a été faite à partir de celle-ci. C'est sans doute l'édition d'Anvers qui supprime la troisième partie [...], et non pas à l'inverse. Cette différence s'explique probablement par le fait que ces deux ouvrages s'adressaient à deux publics au moins partiellement différents : le public madrilène s'intéressaient non seulement à la langue française mais aussi à sa littérature. (2016:44)

6 La diferencia entre las ediciones de 1673 y de 1688 se centra fundamentalmente en las partes en las que se presenta la gramática. Comprobamos así, como destaca M. Bruña que la Gramatica francesa de 1688 comprende tres partes : rudimentos, construcción y arte poética ; que esta tercera parte es considerada por Billet no como un aditamento o un «añadido» (como en la edición de 1673), sino que forma parte esencial de la 
gramática, y « conforme a las artes latinas » (2010b : 233). Por otra parte, comprobamos que 'añade', 'amplía', 'aumenta' las observaciones acerca de los rudimentos, de la construcción, del paralelo entre ambas lenguas (en este caso, en más de un tercio).

Una última modificación debe reseñarse : la edición de la Gramatica de ${ }^{2} 1688$ contiene un breve tratado titulado: Con vna dissertacion critica, sobre vna cartilla, que con nombre de arte, sacò a luz el señor Iuan Pedro Iaròn. Tal 'disertación' no aparece lógicamente en la edición de 1673, puesto que el Arte de P. Jarón fue editado en 1672. En cuanto a la edición de 1708 mantiene el mismo título que la segunda edición, pero desaparece la parte de la Dissertacion critica.

\section{Estructura y carácter de la obra}

8 Se trata, como hemos visto por la lectura del título, de una gramática completa organizada en dos partes (1673) y en tres partes (1688) de un modo particular, y ello constituye ya una de las innovaciones de Billet. En la tradición gramatical española (véanse las gramáticas de Nebrija, Correas y Villar...), el modelo canónico de la organización de la gramática se hacía en cuatro partes : ortografía (y pronunciación), prosodia (y sílaba), etimología o analogía ('rudimentos', partes del oración) y construcción o sintaxis. Tal organización responde a la mecánica propia de la lengua : las letras - unidad mínima de la lengua - se reúnen en sílabas, las sílabas en vocablos, los vocablos en oraciones, según una serie de reglas, cuya descripción corresponde al arte gramatical.

9 La Gramatica francesa de Billet (1688) aporta en cuanto a su estructura varias novedades importantes en relación a la edición de 1673 :

10 - En primer lugar, reúne en una primera parte la pronunciación y ortografía (cap. I a VI) y las partes de la oración (cap. VII a XVIII), folios 1 a 111 según el índice de la edición de 1688.

11 - La introducción de un «Paralelo de la elocuencia francesa y española, y española y francesa ", muy extenso, del que nos ocuparemos más adelante (folios 169 a 276).

12 - La elevación de la "prosodia» al rango de parte fundamental de la gramática, transformándola en « Arte poética », y situándola al final de la gramática, como tercera parte, es decir, como culminación de los estudios gramaticales (folios 277 a 320). El título de dicha parte no deja lugar a dudas : «Gramatica francesa. Tercera parte. Que contiene el arte poética ».

13 La Dissertacion critica, [...] sobre vna cartilla, que con nombre de arte de lengua Francesa, según la nueva corrección de Richelet, sacò a luz el señor Iuan Pedro Iaròn (páginas 1 a 32). En la que muestra un " grand mépris pour Jaron » (Yllera $2016: 50$ ).

14 Contiene por otra parte una «Epístola dedicatoria al curioso » (p. 1-4), así como un «Indice de los capítulos y observaciones contenidas en ellos » sumamente precisa y extensa ( $₫ 8$ páginas!).

15 Billet no explica en ningún momento las razones de tal elección en cuanto a la estructuración de su obra : ahora bien, su conciencia lingüística acerca de lo que es una gramática, heredada de la tradición, está fuera de toda duda : al inicio de la exposición del capítulo sobre las letras, encontramos el siguiente comentario :

Las Letras son, respecto de las lenguas, lo que las notas en la Musica. De estas se forman varios, è innumerables tonos, cuya dulce suaue armonía halaga, y con 
sonora eloquencia persuade. De aquellas se componen infinitos conciertos de vozes, cuya discreta, y eloquente melodía, pinta los conceptos, y retrata lo invisible. Unas, y otras, escritas, hablan à los ojos ; pronunciadas, al oído : sin la noticia perfecta de las notas, ninguno puede preciarse de Musico: sin el entero conocimiento de las letras, nadie puede presumir de saber son primor alguna lengua. (Billet $1688: 1-2)$

Podemos afirmar que es su larga experiencia como maestro de lenguas (el « intento que ha tenido de servir » a los estudiosos, como indica en la Dedicatoria) y su propia afición por la poesía lo que motivan que su obra ofrezca tal estructuración. Pretende componer una gramática completa de la lengua francesa, y en su Dedicatoria al lector pide comprensión por si algún olvido se ha producido, a la vez que subraya que ha aprovechado las advertencias que le hicieron llegar los lectores con respecto a la primera edición.

La inclusión de una parte destinada a la « versificación » era corriente en las gramáticas de una lengua destinadas al público autóctono, como señala M. Bruña (1996: 410); ahora bien, ello es una novedad absoluta en las gramáticas para extranjeros. Así, la Grammaire et syntaxe françoise de Ch. Maupas (1625) está estructurada en capítulos sueltos (sin agruparse en forma de libros, como en Nebrija), dedicados a 'des lettres et de la prononciation', 'des diphtongues', 'de l'article', 'du nom' (y sucesivamente, las diferentes partes de la oración), incluyendo las observaciones acerca del uso (construcción) de cada parte de la oración a continuación de cada una de ellas. La ausencia de un "Índice de los libros o capítulos", como existe en la Grammatica de Cisneros (1635) dificulta, enormemente la utilización de su gramática por parte de un aprendiente, que queda sumergido en la profusión de observaciones. De ahí que Stéfanini haya clasificado dicha obra dentro de la categoría de grammaire des observations (1994).

Hemos afirmado que Billet es plenamente consciente de lo que es una gramática, un arte gramatical, de su contenido o partes de que debe constar como organización lógica del contenido científico. Reprocha precisamente a su rival P. Jarón el haber titulado su obra como " arte » cuando contiene sólo los rudimentos, y apela a la autoridad de la gramática de Nebrija para apoyar su propia elección en cuanto a la estructuración de su gramática ${ }^{1}$ :

[...] sin copia de frases, ó expressiones selectas, tan vtiles como se sabe, á la enseñanza de las lenguas : $y$ finalmente, sin tratado de Poesia, que corresponde al lib. 5. de Nebrija : circunstancias todas tan essenciales á vn Arte, y que le Detuueme en la voz Arte, y sin passar á leer la Epistola Dedicatoria, la Aprobación, ni el Prologo quise especular, discurriendo velozmente por todos los capitulos, si tenia esta fabrica todas las partes de que se deue componer vn Arte, y que ofrecia el pomposo titulo de Arte de la lengua Francesa, y reconocí estaua reducida a los solos primeros rudimentos, sin tener Sintaxis, ó tratado de oracion, que corresponda al libro 4. (Billet 1688 : Dissertacion critica, p. 3)

La voluntad de componer una gramática completa, el mantenimiento de una organización canónica en lo esencial, con las modificaciones señaladas (reunión de pronunciación y partes de la oración en una primera parte ; el relieve concedido al Arte Poética), y el aporte de un índice sumamente preciso y extenso (al contrario que en Maupas o en Jarón) nos llevan a considerar la Gramatica francesa de Billet como una obra gramatical que se inserta de lleno en la tradición gramatical española de las gramáticas racionales. Por otra parte, la presencia del Paralelo de la eloquencia, en el que Billet reúne innumerables modos de hablar propios de cada lengua, que otros autores como Maupas integran en el uso de las partes de la oración a modo de observaciones, nos indica dos 
cosas, a nuestro entender : la propia conciencia gramatical del autor, al no considerar los modos de hablar como elementos que puedan formar parte de la descripción gramatical, y en todo caso propias del diccionario ; en segundo lugar.

\section{Adaptación}

20 Una de las premisas que presiden como hipótesis de trabajo este aspecto particular del análisis consiste en la idea según la cual el carácter de la obra viene determinada en última instancia por el público a quien se dirige. D. Fischer, en su estudio de $1996^{1}$, se limita a indicar que la Gramatica francesa de Billet « [T] out en se voulant pratique, [elle] désire donner une série de normes et conseils au gentilhomme soucieux de la correction de son français et curieux des différents contrastes que présentent les deux langues. Elle s'adresse, en fait, à l'honnête homme' du XVII siècle " (1996 : 214). La biografía de Billet (véase M. Bruña, 2010b) nos informa en efecto que Billet era maestro de lengua francesa en la corte española, y que su 'clientela' estaba compuesta básicamente por nobles deseosos de aprender francés. B. Lépinette indica por su parte, citando la edición de 1708, que Billet «avait un public constitué de courtisans et de princes et de leurs ambassadeurs ", pero también de " quienes se veían en la obligación de comerciar en ambos mundos » (« Aprobación », fol. 4). «Sa clientèle (dont il a peutêtre magnifié le statut social pour des raisons de prestige), aurait donc étudié le français surtout dans un but d'échanges communicatifs utilitaires » (1996b:190)².

21 Lo que si es cierto, puesto que Billet mismo lo afirma en la introducción del Paralelo (1673: folio 101/1688: 169), es que Billet, además de enseñar francés en la corte española, enseñaba igualmente la lengua castellana «à diversos señores, que de las naciones Estrangeras, vna peregrina curiosidad, ò sus negocios, traxeron à esta Corte ». Igualmente, con toda probabilidad, entre 1688 y 1708, Billet aumentó su prestigio como maestro de lenguas, diversificando su clientela de interesados en la lengua francesa con el advenimiento de los Borbones al trono español. Ahora bien, Billet no introduce variaciones en su obra en función de tal diversificación de aprendientes entre la segunda y tercera edición, y no muestra por ello ninguna voluntad de adaptar su obra a los nuevos aprendientes.

22 La Aprobación de Francisco de Barrio (que solo se encuentra en la edición de ${ }^{2} 1688$ ), subsiguiente, indica por otra parte, repetidas veces, que la obra de Billet será bien acogida en la corte española : " y todos los cortesanos debidamente agradecidos a este beneficio, deben estar agradecidos, como he insinuado, darle repetidas gracias » (1688: 5), al ofrecerles el autor un medio infalible para aprender dos lenguas : «aprendiendo otra lengua, además de la suya propia, con los fáciles preceptos que propone à su inteligencia este Nebrija de la Francesa Gramatica » (ibid., 5).

23 La Dedicatoria (al 'Curioso', al 'aficionado', 'al lector') del propio autor no precisa el público a quien dirige su obra, abriéndose a cualquier interesado por la lengua francesa :

El dedicar un libro, siendo un acto libre, pareceme que el acierto de él, consiste particularmente en la elección del sujeto a quien se dedica, y que assi, no puedo lograr mejor mi intento, que en consagrar esta Gramatica mia al Curioso, pues consigo el fin à que mis fatigas se han dirigido; y con una victima sola, hago infinitos sacrificios. Ninguno avrà, que se incline à leer esta Obra, ò movido del deseo de la novedad, ò precisado, para sus fines particulares, à valerse de los preceptos que contiene, que no se persuada justamente à que tiene acción à esta 
Dedicatoria, y que por lo consiguiente no me agradezca mi desvelo, y no corresponda à mi intención, con la estimación devida al intento que he tenido de servirle. $(1688: 1-2)$ por las lenguas en la sociedad española de la segunda mitad del siglo XVII, o bien al interés práctico de otros ( los fines particulares ») como resortes para emprender tal estudio y utilizar sus preceptos, trasladándoles el esfuerzo (el 'desvelo') que el autor ha empleado en componer su obra y mostrando algunas prevenciones acerca de que sea de su gusto y estimación. Se defiende así de antemano de posibles críticas (omisiones, dudas...), de las que no se libran ni los grandes autores, destacando en esa " confesión ingenua » que la composición de su gramática le ha costado 'desvelo', 'meditación', 'inspección', no buscando la 'engañosa lisonja' del lector sino el «intento [...] de servirle». Está convencido así («sé con certidumbre») que su obra «hallará una acogida favorable », puesto que quienes desean aprender conseguirán el conocimiento deseado y podrán apreciar su obra justamente :

pues solo và consagrada à quien ansioso de saber lo que enseña, la solicitare, y la buscare deseoso. Y como à la curiosidad se sigue ordinariamente el conocimiento, espero, que no solo hará de ella el aprecio que puedo desear ; pero, que la conciliarà también la estimación anticipada de aquello, que no la huuieren visto (1688: 3 ).

Francisco de Barrio se siente en la obligación de resaltar una idea no por profusamente repetida ignorada en esa España del siglo XVII, a saber el valor de saber lenguas: «Opinion es recibida de todos, y muy acreditada en todo el Oriente, que vn hombre vale otros tantos hombres, como lenguas sabe » (ibid., 4), mostrando con ello la escasa afición existente en España por saber lenguas, e incitando a los lectores a tal aprendizaje.

Podemos concluir que la Gramatica francesa de Billet se dirige predominantemente a los nobles que frecuentan la corte española del rey Carlos II, por tanto de la mediana y alta nobleza ("principes», embajadores, diplomáticos), y secundariamente, a algunos administradores o comerciantes que pudieran relacionarse con la corte. Ahora bien, no por ello su obra (y por tanto, el aprendizaje de la lengua francesa) posee un carácter frívolo o poco serio. Recordemos que los nobles no habían estado sometidos a la dura escolarización de quienes asistían a las escuelas de primeras letras o a los colegios de latinidad, sino a una instrucción flexible a través de un preceptor, y que por tanto no estaban acostumbrados a someterse a una disciplina intelectual exigente. La dedicación y el esfuerzo con que Billet ha compuesto su obra exigen al lector una misma seriedad en su estudio, y quienes se acercan a su obra deben saberlo, y así lo expresa en su Dedicatoria. La Aprobación de Francisco de Barrio resalta por su parte la calidad del autor aupándole al rango de "Nebrija de la Francesa Gramatica", destacando "los fáciles preceptos que propone a su inteligencia » (ibid., 5) : advierte al lector que está ante una "gramática ", por tanto un arte serio y exigente, si bien la calidad del autor hace fácil su aprendizaje. Así, el autor interviene frecuentemente en su obra para guiar el proceso de aprendizaje de sus aprendientes, y darles ánimo :

Ya salió el curioso de las dificultades de la primera, y segunda conjugación, que nos han sido grandes, respecto de no tener la primera mas de vn verbo anómalo [...]. Sigame, pues, el curioso, y vamos juntos superando las dificultades de las demás conjugaciones que si bien dixe, eran mas irregulares que las demás, también advertí eran pocas, y las dos primeras ya vencidas, se asseguran superar à estas. (Ibid., 95) 
pretende así que el aprendiente no se desanime en su esfuerzo de aprender la lengua francesa por medio de una gramática. La adaptación de la gramática al público al que destina su obra supone ciertamente, y en primer lugar, un tratamiento pedagógico del contenido, del que la aproximación racional a la lengua forma parte: organización lógica del contenido y presencia de un índice extenso, que muestra la minuciosidad y rigor con que la organización de los componentes de la gramática es tratada. El tratamiento pedagógico se revela igualmente en la presencia de tablas (Tabla de los comparativos, p. 54 ; Tabla de los números cardinales, p. 55...), de frecuentes « notas» (o pequeñas observaciones, véase p. 101-111), de ejemplos (en particular, de los diferentes tipos de oraciones, p. 126-130), de una Introducción explicativa al Paralelo (p. 169), de un Proemio al Arte Poética (p. 277). Billet quiere convencer al lector, ganarle en su empresa, no solo facilitando un aprendizaje ordenado, sino en la transmisión de la existencia de un orden en la lengua, y de la necesidad y utilidad de saber las diferentes partes de que consta.

Si el tratamiento pedagógico del contenido revela ya un gran esfuerzo de adaptación, son el Paralelo de la eloquencia y el Arte Poética los componentes más sobresalientes de la adaptación de la obra al público a quien la destina el autor.

El Paralelo de la elocuencia ha sido objeto de un estudio detallado por parte de D. Fischer (1996): destacamos por tanto alguna de sus conclusiones, y aportamos alguna consideración no presente en dicho estudio. Es preciso indicar, en primer lugar, que el Paralelo constituye una novedad absoluta en sí mismo (como tratado lingüístico) y en cuanto a su presencia en una obra gramatical. En cuanto tratado lingüístico, se diferencia del diccionario puesto que están seleccionados únicamente las locuciones, los modos o maneras de hablar, los giros, las expresiones particulares, las 'frases', las 'circumlocuciones'... propios de cada idioma ${ }^{3}$, es decir los hispanismos y galicismos correspondientes. La envergadura de tal tratado sorprende igualmente: más de cien páginas, aproximadamente la mitad para cada lengua (p. 173-210 para las expresiones españolas, y p. 211-276 para las expresiones francesas). En cuanto a su presencia en una obra gramatical, debemos decir que se trata de una novedad absoluta dentro de las gramáticas del francés para españoles. que : « ni le Tesoro d'Oudin (1607), pas plus que celui de Covarrubias (1611, $2^{\mathrm{a}}$ ed.), ni la Grammaire espagnole expliquée en françois de César Oudin (1619, 3a ed.) Refranes o proverbios (1659) ne sont sa source ». Billet conoce el Tesoro de C. Oudin, ciertamente, y lo cita en la introducción al Paralelo, y habrá recogido una serie de expresiones ${ }^{4}$, pero indica que sobre todo lo que ha hecho ha sido corregir los barbarismos presentes en el mismo : «en él hallarà el curioso, si no todos los modos de hablar de nuestro Idioma, por lo menos purgados de sus barbarismos, aquellos, que en el Diccionario de Vdin tienen vna explicicion errada en la materia, y en la forma : y los mas que se añadieron, con la significacion mas propia, y mas adecuada, que pudo hallarse en romance " (ibid., 70). Billet utiliza fundamentalmente su propia experiencia como maestro de lenguas en la corte (más de 23 años en la segunda edición de la gramática), y proporciona como garantía de corrección « los Cortesanos mas cursados, y mas Criticos en el Idioma Castellano » (ibid., 70-71).

31 No podemos dejar de resaltar finalmente una segunda novedad, que D. Fischer destaca igualmente (1996: 217): la discriminación de las diferentes expresiones según los « modos usados en estilo»: "modos de hablar selectos » frente a « vulgares », estilo 
figurado pero sencillo o de uso común. Algunas expresiones son calificadas de "vulgaridades", que pueden tener particular gracia, pero que no se han de usar en «materias serias». Hace preceder así las diferentes expresiones de una estrella, una cruz, una estrella y una cruz, una cruz y una estrella, o las deja sin señalización alguna, para indicar los diferentes registros estilísticos de lengua. En cuanto al rigor con que Billet realiza tal clasificación de las expresiones según los criterios estilísticos de la época (bajo, medio, alto), nos limitamos a consignar el análisis de D. Fischer :

En fait, il semblerait que Billet ait distribué un peu au hasard ses croix et étoiles. Il n'est qu'à comparer les deux parties du Parallèle pour s'apercevoir que beaucoup d'expressions qui, dans la partie espagnol-français, portent une marque, ne la porte plus, ou en porte une autre dans la partie français-espagnol. Nous constatons donc une fluctuation dans les marques qui dénote une certaine fantaisie et un manque de rigueur. Billet place ses étoiles et ses croix généralement devant l'expression, mais on les trouve aussi derrière. Ce qui est important de noter, c'est surtout cette prise de conscience de niveaux de langue, de registres différents, même si Billet ne dispose pas encore de rigueur et de méthode pour les expliquer, il en a du moins le pressentiment et cherche à transmettre ces notions de «bon usage » ou d'usage « familier » à son lecteur. (1996: 218)

Entendemos por nuestra parte que la influencia de los remarqueurs franceses (Vaugelas, Bouhours, Ménage...) se deja fuertemente sentir en la confección del Paralelo, en cuanto a la distinción en francés de una lengua culta y de una lengua vulgar, y en cuanto a la concepción de que la nobleza de un país debe cuidar su lengua, su estilo, no cayendo en vulgaridades y empleándola con corrección y elegancia. Tal afirmación la apoyamos en las observaciones que efectúa Billet en la «Dissertacion critica » : se muestra contrario a que haya sido Richelet el que ha reformado ("corregido») la lengua francesa; Richelet únicamente ha recogido en su Diccionario lo que « los hombres eminentes [...] han escrito y escriuen en nuestro Idioma » (1688: Dissertacion critica, 4) :

En vna misma fuente hemos bebido ; y si bien ha 24 años, que estoy en esta Corte, los mismos raudales en que puede auer apagado la noble sed, que han tenido de saber, han pasado hasta à mi, muy puros, y limpios : y todas las expresiones, y frase de el Paralelo de la Eloquencia de mi Gramatica, estàn sacadas de los mismos manantiales. (Ibid., 4)

Por ello, el Arte Poética es el complemento necesario de su gramática, la culminación del estudio de la lengua.

El Arte Poética constituye el tercer componente importante de la adaptación de la obra gramatical de Billet al público al que se dirige. No compartimos la apreciación de B. Lépinette, cuando afirma que: "la présence d'un traité de versification à la fin du recueil, qui n'est pas en cohérence avec une visée pratique, peut rendre douteuse cette dernière finalité » (1996b: 190). Entendemos que B. Lépinette se deja guiar por el comentario de Don Esteban Cruzado y Ferrer, en su Aprobación de la edición de 1708, quien señala entre los aprendientes interesados por la obra de Billet a comerciantes y mercaderes, y asignando una función práctica a la obra, es decir, la de aprender a hablar la lengua. Desde nuestro punto de vista, la Gramatica francesa de Billet posee una marcada finalidad práctica, pero comparte con dicha finalidad - y de ahí el Paralelo - la de hablar con corrección, y decoro y elegancia (término que se repite en varias ocasiones a lo largo de la obra, véase por ejemplo, 1688: 167). Este Arte Poética iba dirigida a algunos discípulos de la corte como el propio Francisco De Barrio «qui s'adonnaient volontiers à l'art de la poésie", (Yllera 2016: 45). Numerosas observaciones de su Dissertacion critica acerca del Arte de Jarón están motivadas 
precisamente por corregir explicaciones y observaciones que Jarón expone, y que Billet considera incorrectas, en cuanto a la pronunciación, en cuanto a traducciones, en cuanto a la exactitud de las formulaciones : no podemos extendernos en ello.

Billet estima que la " estimación viene del conocimiento », y por ello incluye el tratado sobre la poesía francesa (en forma de 'compendio') al final de su obra gramatical. El Proemio del Arte Poética marca como objetivo "aprender à conocer los versos y a componerlos » (1688: 278); se opone a la idea según la cual los versos por ser fáciles e inteligibles, no han de ser buenos, criticando así el obscurantismo y el gongorismo de la poesía española de la época.

\section{Conclusión}

La particular adaptación que Billet emprende de la Gramatica francesa, nos produce una serie de interrogantes. Hemos afirmado que el carácter de la obra viene determinada en última instancia por el público a quien se dirige. El tipo de aprendientes ayuda a explicar el carácter específico de la obra gramatical (grammaire formatrice o racional, grammaire des observations, gramática práctica, gramática simplificada a unos meros rudimentos o paradigmas), así como sus componentes, su organización de los mismos. Ahora bien, la Gramatica francesa de Billet no puede explicarse, a nuestro entender, de modo mecánico, por el tipo de aprendientes a los que el autor dirigía su obra. Pensamos que Billet impone su sello particular en su gramática, fruto de su formación, de sus gustos (como hemos indicado anteriormente), del modo de concebir la lengua (como conjunto de elementos sometido a reglas, como marca de distinción de una persona noble, como uso elegante y culto). No podemos a este respecto sino señalar - además de la comparación de las letras con las notas de música que efectúa al comienzo del capítulo sobre las letras, siendo las frases como las melodías musicales, que ya hemos señalado - otra metáfora sumamente expresiva de la concepción de la lengua, esta vez como construcción, que sitúa al comienzo de la parte segunda, dedicada a la oración :

Es la oración el fin principal de la Gramatica, y las partes de que hasta ahora hemos tratado, son los medios que nos conducen à él. Estos son los materiales, aquella es el edificio, y como la Simetria hermosea las fabricas, con particular cuidado atenderemos a guardar en esta nuestra, toda la orden, y la proporción posible, para que no desdiga de los preceptos de su Arquitectura. (1688:113-114)

La construcción que cada aprendiente, cada usuario de la lengua, efectúa a partir de los materiales de la lengua debe ser un edificio bello, sometido a las reglas de la simetría y de la proporción. Tal ideal lingüístico persigue Billet en sus aprendientes, objetivo nítidamente relacionado con el tipo de público a quien destinaba su obra, cierto ; pero objetivo que es fruto igualmente de su particular concepción de la lengua y del valor que esta representa.

Estimamos así que la adaptación de la obra gramatical de Billet sufre un doble proceso de adaptación, que funciona de modo dialéctico, y no meramente mecánico : del autor hacia la obra, por una parte ; de los aprendientes hacia la obra, por otra parte ; o bien, para representar ambos movimientos de modo dinámico : del autor, en presencia de unos aprendientes dados, en función de una experiencia de enseñanza, y de una determinada concepción de los objetivos pretendidos, hacia la obra. 


\section{BIBLIOGRAPHY}

Fuentes primarias

BILLET, Pierre Paul (1673). Gramatica francesa : dividida en dos partes [...]. Zaragoza : [s.n.].

BILLET, Pierre Paul (1688). Gramatica francesa, dividida en tres partes.[...]. Madrid: imprenta de Bernardo de Villadiego. Otras ediciones : Henrico y Cornelio Verdussen, 1687 ?; Madrid : Juan García Infanzón, ${ }^{3} 1708$.

CHIFFLET, Laurent (1680 [1659]). Grammaire de la langue françoise [...]. Bruxelles : Chez Lambert Marchant. La edición de 1659 lleva como título : Essay d'une parfaite grammaire de la langue françoyse.

MAUPAS, Charles (1625 [1607]). Grammaire françoise [...]. Blois : Ph. Cottereau. Reed. 1618, 1625, Grammaire et syntaxe française [...]. Paris : chez Adrian Bacot. 1635 sin cambios. Genève : Slatkine Reprints, 1673, a partir de la edición de 1618.

NEBRIJA, Antonio de (1488). Introducciones latinas [...]. Reed. 1773. Madrid : Imprenta de D. Joachín de Ibarra.

oudiN, César (1632). Grammaire françoise rapportée au langage du temps. Paris : P. Billaine. Nueva ed. más completa en París : A. de Sommaiville, 1640.

OUDIN, Antoine (1660). Nouvelle Grammaire espagnole et françoise [...]. Paris : L. Chambardry.

Fuentes secundarias

BRUÑA CUEVAS, Manuel (1996). « Le problème de l'orthographe française dans les grammaires de français à l'usage des espagnols et dans les dictionnaires bilingues français-espagnol et espagnolfrançais (XVI ${ }^{\mathrm{e}}-\mathrm{XVIII}{ }^{\mathrm{e}}$ siècles) ». In E. Alonso et al. (éds.). La lingüística francesa : gramática, historia, epistemología. Sevilla : Grupo Andaluz de Pragmática, 85-102.

BRUÑA CUEVAS, Manuel (2010a). «Pedro Pablo Billet es el autor del Arte para aprender (...) la lengua francesa (1672) ». In J. C. de Miguel et al. (éds.). Enfoques de teoría, traducción y didáctica de la lengua francesa. Estudios dedicados a la profesora Brigitte Lépinette. Valencia : Universitat de València, 103-112.

BRUÑA CUEVAS, Manuel (2010b). «Dos maestros de francés en el Madrid de finales del siglo XVII : Pierre-Paul Billet y Jean-Pierre Jarón ». In M.-H. Maux-Piovano (éd.). Enseigner les langues modernes en Europe, $\mathrm{XV}^{e}-\mathrm{XVII}{ }^{e}$ siècles. Strasbourg : Université de Strasbourg, 219-260.

FISCHER HUBERT, Denise (1996). « La Gramática Francesa de P. P. Billet : contenus et méthode ». Documents pour l'histoire du français langue étrangère ou seconde, 23, 213-223.

FISCHER HUBERT, Denise (2000). « Le traitement des temps verbaux chez Pedro Pablo Billet, avec une comparaison de sa terminologie avec celle d'autres grammairiens ». In J. de Clercq et al. (éds.). Grammaire et enseignement $d u$ français, 1500-1700. Leuven/Paris/Sterling-Virginia : Peeters, 533-553. LÉPINETTE, Brigitte (1996). « Les premières grammaires du français (1565-1799) publiées en Espagne. Modèles, sources et rôle de l'espagnol ». Histoire Épistémologie Langage, t. 18-2, 149-177.

LÉPINETTE, Brigitte (1996b). « Contribution à l'histoire du français hors de France. Caractéristiques culturelles et sociales des maîtres et de leur enseignement en Espagne au XVIII ${ }^{\mathrm{e}}$ siècle ». Documents pour l'histoire du français langue étrangère ou seconde, 18, 189-212. 
LÉPINETTE, Brigitte (1997). « Deux grammaires françaises pour Espagnols (XVII ${ }^{\mathrm{e}}$ siècle). Traditions grammaticales nationales et pédagogie ». Linguistique Investigationes, 21, 199-239.

LÉPINETTE, Brigitte (2000a). « El análisis contrastivo en la gramática francesa editada en España durante el siglo XVIII ». In Maqueira Rodríguez et al. (éds). Actas del II Congreso Internacional de la Sociedad Española de Historiografía Lingüística (León, 2-5 mars 1999). Madrid : Arco Libros, 631-644.

LÉPINETTE, Brigitte (2000b). L'enseignement du français en Espagne au XVIII ${ }^{e}$ siècle dans ses grammaires. Contexte historique. Concepts linguistiques et pédagogie. Münster : Nodus Publikationen.

STÉFANINI, Jean (1994). Histoire de la grammaire. Paris : CNRS Éditions.

SUSO LÓPEZ, Javier (2011). « De la gramática francesa explicada en español a la gramática francesa para españoles en el siglo XVIII : gramática general, gramática particular y gramática contrastiva ». In J. Villoria (éd.). Historia de la ideas lingüísticas. Gramáticas, diccionarios y lenguas (siglos XVIII y XIX). Frankfurt : Peter Lang, 51-90.

SUSO LóPEZ, Javier (2014). « Le discours des auteurs de grammaires françaises pour hispanophones (XVI ${ }^{\mathrm{e}}-\mathrm{XVII}{ }^{\mathrm{e}}$ siècles) ». Langue Française, 181, 59-78.

VIÉMON, Marc (2016). L'apprentissage de la prononciation française par les Espagnols aux XVI ${ }^{e}, \mathrm{XVII}^{e}$ et $X V I I{ }^{e}$ siècles. Sevilla : Universidad de Sevilla. Thèse de doctorat dirigée par Manuel Bruña et soutenue le 26 février 2016.

YLLERA, Alicia (2016). « Deux grammairiens français du XVII ${ }^{\mathrm{e}}$ siècle en Espagne et leur enseignement de la prononciation française : Pedro Pablo Billet et Juan Pedro Jaron ». In Antonio Gaspar Galán \& Javier Vicente Pérez (éds.). Histoire de l'enseignement de la prononciation du français aux Espagnols (XVI ${ }^{e}-X X^{e}$ siècles). Bern, etc. : Peter Lang, 43-62.

\section{NOTES}

1. Remitimos a los trabajos de M. Bruña para conocer detalles de la biobibliografía de Billet (2010b : 222-229 y 235-242).

2. La modalidad utilizada por Sotomayor (rudimentos gramaticales en español y en francés expuestos en columnas paralelas), se agota con la reedición por Lacavallería. En cuanto a la Grammatica de D. de Cisneros, y tomando como referencia la edición de 1635, su propio carácter de gramática racional (o formatrice, en la denominación utilizada por B. Lépinette [1996a : 154]) no va a constituir el fundamento de una manera de enfocar y de componer una obra de índole gramatical.

1. Se refiere Billet a las Introduciones latinas, editado en 1488. El libro V está dedicado precisamente a «De la cantidad de las sílabas, pies, versos y acentos» (1673 : 208-252). Al igual que Buffier, cuya gramática (Grammaire française sur un plan nouveau, 1709), que contiene un tratado « sur la beauté des langues et la manière de les apprendre » (página del título), como una tercera parte sobre la "pratique pour le style», ejercerá una profunda influencia en las gramáticas francesas del siglo XVIII, entre otros motivos por su condición de padre Jesuita y la adopción de esta gramática en los colegios de esta orden religiosa.

1. En 2000 no analiza dicha cuestión.

2. Se trata de la Aprobación de Don Esteban Cruzado y Ferrer, que no figura en la edición de 1688.

3. Utilizamos las diferentes denominaciones de las mismas utilizadas en la época y en Billet.

4. Habría que emprender un estudio preciso para determinar el grado de influencia de dicha fuente, así como con respecto a los « remarqueurs » en cuanto a las expresiones francesas. 


\section{ABSTRACTS}

By bringing together and analyse different studies, so far scattered and partial, published on Pierre-Paul Billet (Fischer 1996, 2000 ; Lépinette 1997, 2000 ; Bruña 2010a, 2010b ; Suso 2011, 2014 ; and more recently, Yllera 2016 ; Viémon 2016, doctoral thesis), this article aims to provide an overview of Billet's grammar. While its main purpose is to illustrate the contributions and innovations that the author introduces in his grammar to adapt it to a Spanish-speaking public, this study will also take into account the grammars of that time (such as Chifflet's). This overview will allow not only to better understand the quality of Billet's work as foundational in respect of the French grammars published in Spain in the $18^{\text {th }}$ century, but also to highlight some profiles that have not been studied yet and which show the Author's profound originality.

Grâce au rassemblement et à l'analyse des différentes études, jusqu'ici dispersées et partielles, publiées autour de Pierre-Paul Billet (Fischer 1996, 2000 ; Lépinette 1997, 2000 ; Bruña 2010a, 2010 b Suso 2011, 2014 ; et tout récemment, Yllera 2016; Viémon 2016, thèse doctorale), cet article vise à donner une vision globale de la grammaire de Billet, en prenant comme objectif principal l'exposition des contributions et des innovations que l'auteur introduit dans sa grammaire pour l'adapter à un public espagnol, et en tenant compte des grammaires de l'époque (en particulier, celle de Chifflet). Cette vision d'ensemble nous a permis non seulement de mieux comprendre sa qualité d'ouvrage fondateur des grammaires de français éditées en Espagne au long du XVIII ${ }^{\mathrm{e}}$ siècle, mais aussi de découvrir une série d'aspects pas encore mis en relief, qui montrent la profonde originalité de l'auteur.

\section{INDEX}

Mots-clés: grammaires du français pour Espagnols, XVIIe-XVIIIe siècles, Billet

Keywords: French grammars for Spanish, 17th-18th centuries, Billet

\section{AUTHOR}

\section{IRENE VALDÉS MELGUIZO}

Université de Grenade

ivaldes@ugr.es 